\title{
BEYOND VERNACULAR ARCHITECTURE
}

\author{
K. Kovács $1, *$ \\ ${ }^{1}$ Sapientia - Hungarian University of Transylvania - kazmerkovacs@yahoo.com
}

Commission II - WG II/8

KEYWORDS: Vernacular, Intangible heritage, Cultural landscape, Natural milieu, Boundaries

\begin{abstract}
When John Ruskin "discovered" vernacular architecture, it was a rich heritage still in the making. Contrary to most of the other kinds of valuable built remains of cultures gone, vernacular architecture has been well alive, vigorously creative and yet ancient. Besides being continuously inhabited, it has been conserved in open-air museums and reinterpreted through national styles seeking inspiration from it. The former usually resulted in houses turned into museum exhibits; the latter inevitably resulted in compositions designed by trained architects. Alongside this process, there occurred progressive disappearance of vernacular crafts and ways of life. There is, however, a lesson that built vernacular heritage can still teach us: better integration of human settlements to the environment What lies beyond vernacular architecture or the theory and practice of its preservation, is the reinvention of the boundaries of localness.
\end{abstract}

\section{STAGES OF VERNACULAR HERITAGE}

Vernacular architecture is a relative newcomer to the vast and heterogenous domain of built heritage. It emerged in the wake of the industrial revolution and, as a matter of consequence, in England ${ }^{1}$ (Choay, 1999, p. 10). When John Ruskin spoke out praising the memorial value - he called it sanctity - embedded in "a good man's house" (Ruskin, 1889, p. 179) vernacular architecture was a rich heritage still in the making. Contrary to other kinds of valuable built remains of cultures gone, it was well alive, vigorously creative while, at the same time, ancient in spite of its relative newness. Studying and understanding the mechanisms of the slow and consistent evolution through centuries of this anonymous architectural production were meant as a solution to the semantic crisis of European "architecture in the age of divided representation" (Veselý. 2004).

Even if the imminent disappearance of vernacular architecture was not so obvious a century and half ago (as it is today), the emergency of its safeguarding was acknowledged quite early. The establishment of the first open air museums ${ }^{2}$ and the invention of national styles on the basis of shapes, techniques and motifs borrowed from vernacular building traditions remain to this day two major methods put in place for the conservation of these specific values. However, dwellings, churches, mills or barns, once moved into enclosed parks would no longer make up a human settlement. Open air museums try as they might to gather peasant craftsmanship and agricultural practices through innovative museal programmes, true economically functional living and the mood of traditional villages have remained inevitably absent from these places.

Considering the fact that what distinguishes architecture from other visual arts is its usefulness - it is defined by being inhabited (Kant, 1790 p. 178) $)^{3}$ - the collection of artful

\section{* Corresponding author}

Vernacular architecture was indeed integrated in the realm of built heritage alongside "industrial architecture".

The Skansen in Stockholm opened its gates as early as 1891 .

(...) weil die Angemessenheit des Produkts zu einem gewissen Gebrauche das Wesentliche eines Bauwerks ausmacht;" buildings of the past in open air museums is bound to be less than architecture. By not being inhabited, these artefacts cease to be architecture in the proper sense.

"Neo-vernacular" or national styles have been practiced with unequal impetus or success by European architects since the last decades of the 19th century to this day, from the Iberian Peninsula to the shores of the Black Sea (Popescu, 2004; Mansbach, 2018). These attempts often produce original compositions reminiscent more or less of their vernacular sources of inspiration. Responding to modern architectural programmes and designed by trained architects, these buildings nevertheless embody the scholarly knowledge, as well as the idiosyncrasies of their authors in their choice of architectural forms. By all means, the results of such re-creative efforts do not belong to the category of the vernacular.

\section{BUILT VERNACULAR TODAY}

\subsection{Samples}

As so many times before - the longevity of the primaeval shelter motif in the history and theory of architecture is remarkable (Rykwert, 1981) - whenever architects have made recourse to ancient models, the efforts to reshape their kit of artistic tools have materialized by taking another look at the refined specimens bearing witness of past building practices.

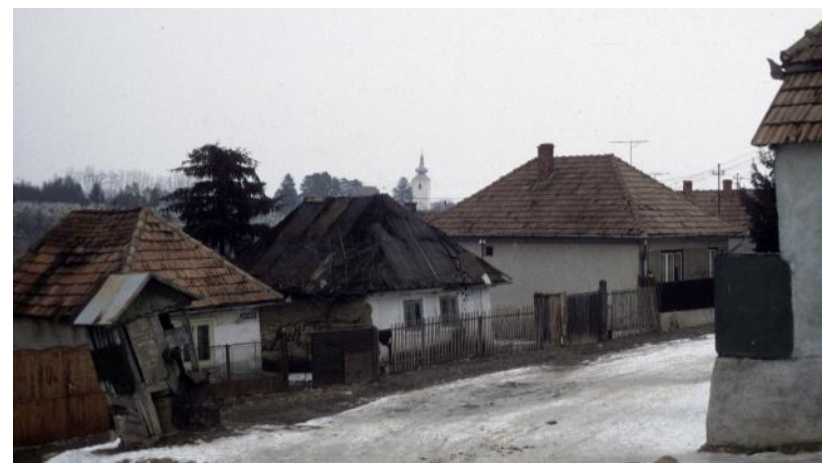

Figure 1. Traditional urban neighbourhood Sf. Gheorghe, Romania. 
We must notice that there is a substantial amount of urban vernacular architecture worldwide that may well be labelled "infra-ordinary" (Pérec, 1989). It consists mainly in dwellings built by craftsmen following everyday models. They are "buildings without architects" (May, Reid, 2010) that bear simplified (some would say corrupted) features of "educated" building styles according to the taste or fashion of their respective times. However, in Romania, valuable vernacular architecture is unanimously considered synonymous with the peasant art of building.

2.1.1 From Balaban to Valea Boroș. Such was the case with the project of the Balaban guest house built to match the bucolic surroundings of a Transylvanian mountain site. In spite of decent architecture and fine craftmanship, the building, which had taken its model from a precious item kept in the Astra open-air museum in Sibiu, turned out to be a confusing instance of a contemporary attempt to replicate on the drawing board what anonymous builders did in the past by tradition ${ }^{4}$.

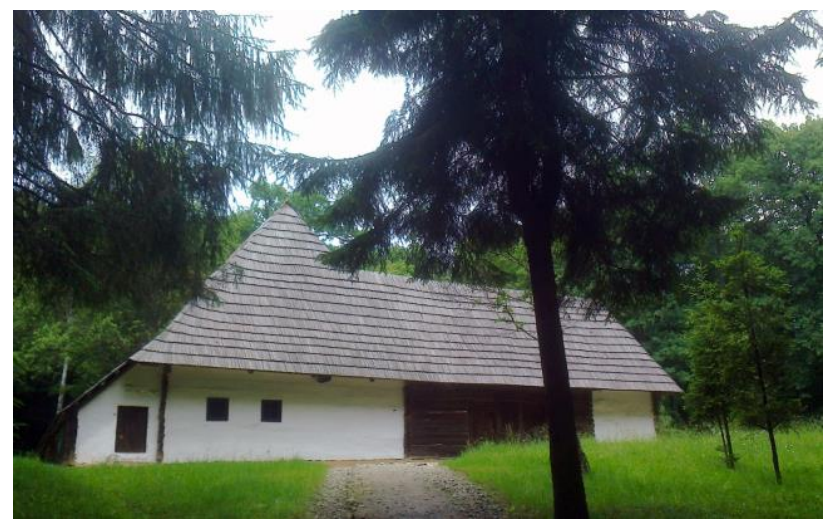

Figure 3. Shepherds' "ocol” from Măgura, 1844 Since 1972 in the Astra Museum, Sibiu, Romania.

Thus, when turned into museum exhibits, vernacular peasant buildings cease to be fully fledged architecture. If their spontaneously developed shapes, techniques, and details are purposefully integrated to cultured projects, the resulting buildings are no longer vernacular. The deadlock implicit in the established modes of conservation for vernacular building traditions is further complicated by the gradual disappearance of vernacular crafts and ways of life. No longer viable in economic terms, this kind of intangible heritage ${ }^{5}$ is mostly kept alive through complex and expensive cultural policies.

These days, people living in villages do much less agriculture than before, embracing instead the urbanite habits of their new neighbours, who escape the strain of city life by moving out to the countryside. It is no paradox then that valuable vernacular architecture is better appreciated and preserved by cultivated village newbies, while genuine villagers progressively discard their traditional dwellings and customs in favour of "modern" houses and way of life.

Eventually, the new (urban) approach of appreciating ancient craftmanship and traditions will prevail, often fuelled by the benefits brought by lucrative activities related to agritourism; the locals will follow suit by preserving alongside their new fellow villagers the still standing traditional buildings.

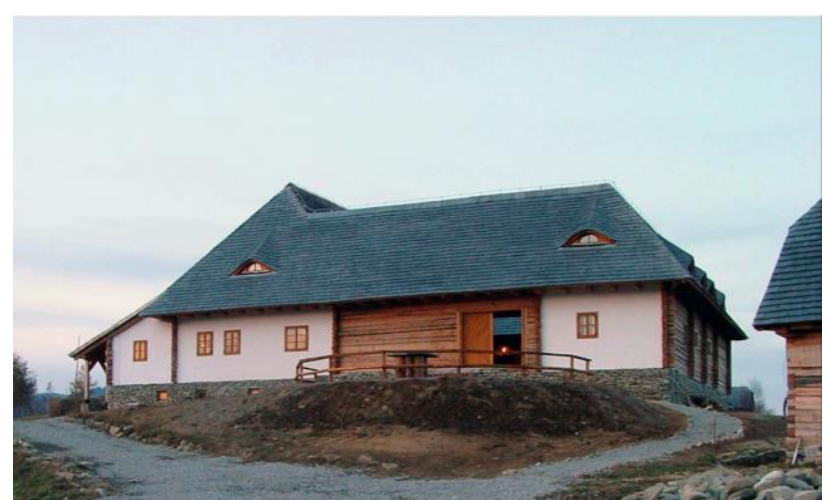

Figure 2. Inn on the Balaban Hill, 2006. Bran, Romania. Attila Zakariás and Kázmér Kovács, architects.

A successful preservation of vernacular heritage would entail the survival of the connected immaterial heritage, since in the absence of adequate craftmanship any endeavour to maintain or to restore vernacular buildings will be doomed.

During the recent decades, restoring and equipping old peasant houses in order to be inhabited by townspeople has become a significant trend in Romania as well. Yet it requires fine tuning to find the right measure between replacing decayed building elements with similarly fabricated pieces, to invent suitable alternatives of elements that can no longer be reproduced, as well as to provide the necessary amount of technical or hygienic accessories for a comfortable dwelling. The task probably takes a somewhat different sort of empathy on the part of the architect than the restoration of more conspicuous items of built heritage.

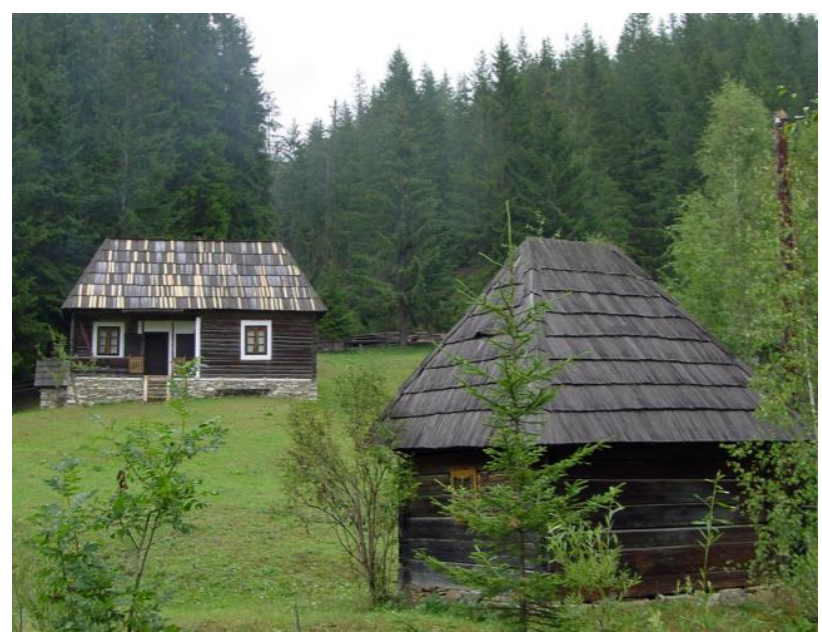

Figure 4. Restored and refurbished house, 19th century.

The "Malom" Foundation, Valea Boroș, Romania.

The privately-owned open-air museum in Valea Boroș ${ }^{6}$ began with the acquisition of a property surrounding an old wooden house, which was restored by its new owner, the architect Attila Zakariás. The museum was developed over the years to become a collection of more than twenty buildings: dwelling houses, barns, stables, baking houses, a mill and even a small a chapel. It became a small colony situated in the upper part of the village, inhabited intermittently by the architect and his friends who contributed to achieving the museum.
The Balaban guest house burnt down in April 2020.

As defined by the UNESCO Convention for the Safeguarding of the Intangible Cultural Heritage, Paris, 2003, Article 2.
6 The "Malom" Foundation, Valea Boroș, Harghita County, Romania. 
2.1.2 From Ciumani to Zetea. Theoretically, the least problematic way of preserving vernacular peasant architecture seems to be its conservation in situ, even when the inhabitants no longer participate to an agricultural way of life. It is the case of a peasant house in Ciumani, where decayed building elements were replaced by authentic copies while also adding the necessary energy and drinking water supplies, hygiene, and communications equipment.

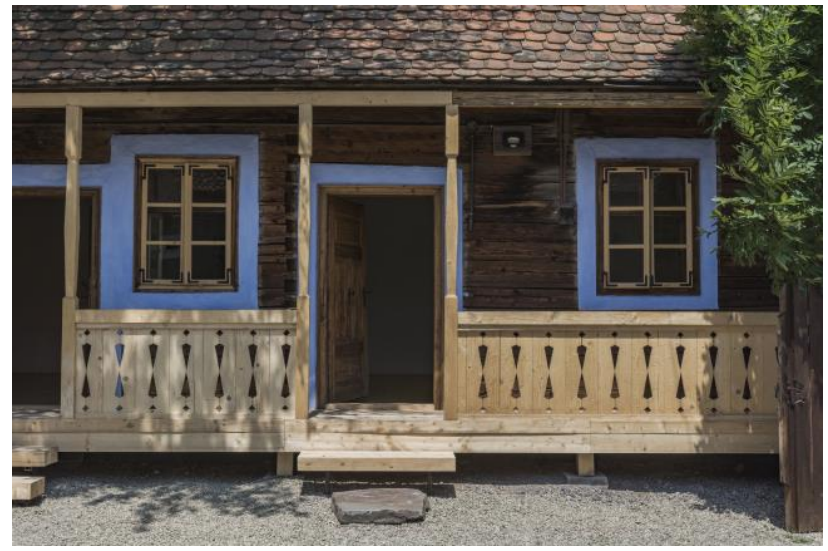

Figure 5. Restored peasant house, 19th century. Ciumani, Romania. Miklós Köllö, architect.

The architect who planned these restoration works is also the author of a fair number of new buildings in the Székely countryside. Boasting a well-balanced combination of traditional and contemporary materials and techniques, these interventions sum up a convincing attempt to build modern while at the same time preserving the cultural landscape.

Efficient preservation in interpretations like these involves inventing professionally valid solutions in order to keep under control the transformations of the anthropic milieu amidst inevitable changes brought about by social, political and economic processes. Freezing vernacular built heritage in an embalmed, finite stage will not be enough to cope with the complexity of the matter, either technically or semantically.

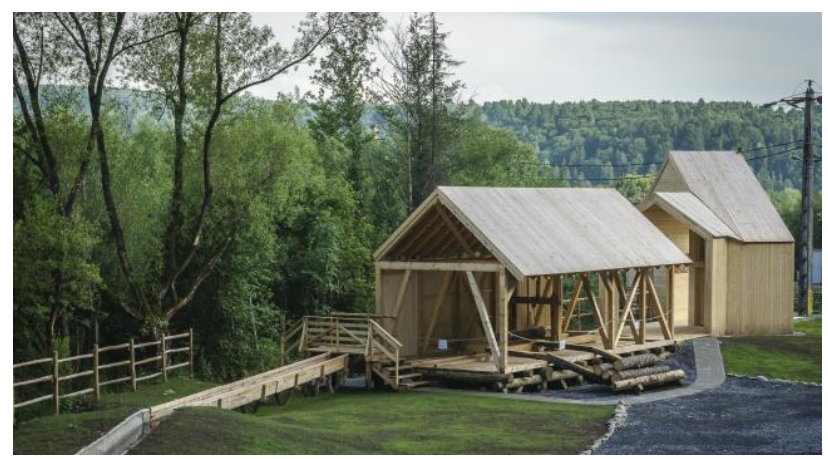

Figure 6. Sawmill, 2016. Zetea, Romania. Miklós Köllö, architect.

Perhaps this is the right place to raise the question of the ethics of architectural aesthetics. Discerning what is right from what is wrong when it comes to architectural meaning is not a relevant issue in the case of genuine vernacular architecture: being spontaneous can hardly be wrong. Instead, it has to become an issue when any cultivated project endeavours to tackle the burden of preserving vernacular building traditions. Besides the elementary concerns for contextual integration there is no infallible recipe; taking into account the difficulties involved by the adequate preservation of authentic buildings, it is not by copying them, but by understanding the spirit of vernacular architecture that newly elaborated projects can aspire to comparable performance.

\subsection{Ethics and aesthetics of vernacular architecture}

Once again, the authenticity of the architectural intervention is at the centre of the matter. The Nara Document on Authenticity issued at the end of a great international gathering ${ }^{7}$, which was meant to finally settle the matter, remains reasonably circumspect in defining the frontiers of the concept. For technical as well as for theoretical reasons, these frontiers become more obvious when they are disregarded - that is when we are confronted with inauthentic interventions (Choay, 2006); hence, there is no doubt that the success of any project aiming at the conservation of built or indeed any kind of cultural heritage shall intervene solely on their material part, while leaving the (intangible) content unspoiled. In this sense, the theoretical framework for the restoration rules established during the postwar period remains undisputed to this day (Brandi, 1963).

2.2.1 Cultural landscape. There is no question that the nearest stage of what lies beyond vernacular architecture is the landscape surrounding it. Being determined by architecture and providing it with a suitable milieu, cultural landscape establishes an uneven relationship between human settlements and natural environment. They go together in the wider project envisaging the controlled transformation of any anthropic milieu. Unavoidable yet manageable, multiple changes brought about by an ever-faster pace of the spreading of global culture make all the more important the task of preserving local specificities - as well as more difficult

Cultural landscape came somehow to be perceived and regulated like any other kind of cultural heritage. Vernacular peasant architecture naturally constitutes a part of it; agriculturally transformed hills, valleys or plains do as well. However, the conservation and management of cultural landscape are in several elementary respects different from those of built heritage, even when conceptualized in similar terms, as is the case for instance in the text of the European Landscape Convention ${ }^{8}$. To set rules, techniques and procedures for the "protection, management, and planning" of landscapes is necessary and useful. Yet indiscriminately amalgamating built heritage and anthropic milieu results more often than not in decisions leading to approaches where the implicit techniques involved may tend to reify the very nature of the limitless (and literally intangible) landscape.

Quite differently from an early-stage romanticism, the motivation to preserve cultural landscape is today a matter of survival. Conservation initiatives need to be done without attempting to give landscape some utopian immutability; plausible approaches belong to a complex, necessarily creative endeavour. It takes a sensitive combination of modern and traditional elements, considering as many of both natural and cultural components of the site as possible, even those bound to remain beyond the reach of the planner (such as climate or seasons). Although the area of the landscape project - of any project indeed - will always be clearly cut out from the wider context, its meaningful implications will by definition be extended as far as the horizon.

The Conference was hosted by Japan in November 1994.

8 Although the phrase "cultural landscape" does not appear as such in the text of The European Landscape Convention (Florence, 2000), the idea of "cultural landscape" is implicit in the numerous occurrences of various heritage values. 


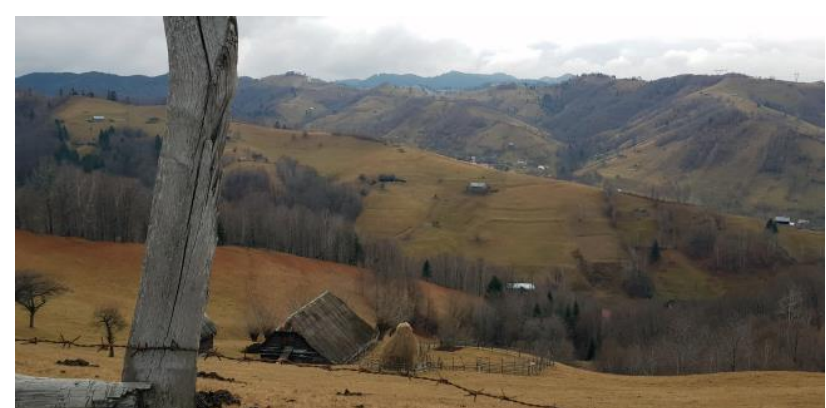

Figure 7. Cultural landscape of alpine pasture. Bran, Romania.

Therefore, the conservation project has to be expanded. It shall henceforth comprise individual buildings as well as their closer and farther vicinity; it will envisage the functional and also the visual relationship of whole settlements with their surrounding fields, topography, vegetation, wildlife. And it needs to be economically viable while exploiting sensibly the available resources.

2.2.2 A new vernacular project: Not only in Renaissance Europe where, apart from China during the Han Dynasty, the concept of landscape reached its most complex sense (Berque, 2000), since the invention of the idea of landscape (involving natural beauty) we are used to react to vistas with a whole series of aesthetic reflexes, as well as to measure interventions with landscaping criteria. However, cultural landscape requires a great deal more than good composition and the mastery of botany. Although the aesthetic dimension accompanies any project at least on a semantic level, the planners' attention will first of all have to focus on ways to reconcile so many economical and functional requirements with any arrangements "pleasing to the sight and good for food"

Vernacular is understood as "local", indicating the place, a locus identified in a natural area by establishing its boundaries and then providing identity to those who belong there, whether people, animals or plants. If one is to go back to the meaning of the word, then doing vernacular today cannot be reduced to imitating ancient practices or way of life. On the contrary: attempts to recreate (or "re-enact") ancient practices in the territory are bound to fail, ending up as either tragedy or caricature. Any future "local project" (Magnaghi, 2003) has to put up with the demographic, economic, and, above all, the ecological concerns of the 21 st century. There can be no going back to pre-industrial societies, let alone pre-agricultural societies.

And there can be no going back to nature either (Ritter, 1997) ${ }^{10}$. At least since the first agricultural (or Neolithic) revolution, the meaning of the human world, by associating meaning to things as well as fabricating them, was to be different, that is artificial. Longing for a golden age past, whether Classical, Romantic or post-modern, means dealing with societies retrieving their long forgotten "natural" habits no less hypothetically than do efforts to create biodiversity scientifically. In this wider context, the significance of vernacular heritage appears to be a ubiquitous, valuable, although vague, fragile and diffuse reference system we can relate to, while trying to find a way amidst our late-

\footnotetext{
${ }^{9}$ Following the model of "every tree" chosen by God when He "planted a garden eastward, in Eden". Genesis 2.8.

10 It is already a well-established view that "landscape"- nature perceived as aesthetic matter - is the result of societies putting a cognitive distance between ourselves as natural beings as opposed to ourselves as cultural beings, even if this dichotomy is a specious one.
}

modern spatial drifts. As a result of our being humans, neither can actual biodiversity coexist with us on the same territory, nor will this state of affairs be different in the future. Different instead, to the point of dramatically shifting the emphasis in any reasonable discourse on conservation, are the very scale of our presence on Earth and the fact that the majority of humans have by now become city dwellers.

From the most ancient of times, city dwellers have had to rely on the agricultural hinterland in order to survive. Unlike cities, while still radically transforming the territory, vernacular peasant households and countryside settlements would not waste their resources. Post-industrial societies must learn to treat natural milieu in similar economical ways.

The endeavour of elaborating a new vernacular project has as much to do with traditional techniques and ways of life as conservation of vernacular architecture has ever had. Eventually the new urban fashion shall prevail and the locals will preserve together with their new fellow villagers what is left of vernacular heritage.

However, it will no longer be sufficient to keep basic techniques and behaviours alive. In order to bear fruit, these crafts need to be perpetually reinvented according to our times, while abandoning the fateful illusion of their possible rebirth. Otherwise, all we can achieve is an expensive collection of splendid and ever scarcer museum exhibits.

\subsection{Metaphorical excursus}

More than depositories of collective memory, disparate but still extant, pieces of vernacular architecture work as a whole: they embody a metaphor of better selves at better times.

Architectural metaphors (Lakoff, Johnson, 2003) are a particularly rich source for expressing abstract notions or emotions (Kovács, 2007) ${ }^{11}$. However, the basic meaning (as well as function) of any built structure is bound to remain its being a shelter. "Having a roof above one's head" is the opposite of "sleeping rough" or, indeed, "sleeping under the stars" - the French correspondent of the latter is "dormir à la belle étoile". Both in Romanian and Hungarian, the collocations signifying the absence of a roof literally translate by "sleeping under the free sky" 12 . Does then such imagery connote that the roof closes off the endless spatiality of the universe? Is there also a menace involved in being sheltered? Do we have to pay the price of security and comfort by giving up our freedom, a privilege shared by all natural beings? If so, the fragility of vernacular heritage also signifies a link to times and customs characterized by a less concealed spatial relationship with nature.

Today, if there is any threat to our "cosmic freedom", this threat neither comes from the untamed wilderness, nor does it emerge from the shelter itself, for the stars are not always there to shine unobliterated. Yet, a considerable danger is represented by the excess of roofs we can afford (supported by foundations, pillars, and beams), by ever larger built structures provided with extensive car parks and accessible from countless roads.

\footnotetext{
${ }^{11}$ We use metaphor in the sense given to the word by these authors who give convincing evidence on the frequent occurrence of architectural metaphors in everyday speech.

12 "A dormi sub cerul liber", respectively "szabad ég alatt aludni”.
} 


\subsection{The idea of a boundary}

To be local amounts then to have defined a place; thus, tracing a boundary has always been the first architectural gesture - and is bound to remain so as long as humans build. Until relatively recently, our settlements small or large had their limits, even though these were continuously exceeded, usually to be reestablished again elsewhere. This cyclical process accompanies the whole history of human settlements (Kotkin, 2006). Beyond a boundary there lies the wilderness: a threatening, untamed realm.

2.4.1 Overstepping the mark: Nowadays the situation is entirely reversed. The "nonplace urban realm" (Webber, 1964) invades more and more territories, indiscriminately engulfing agricultural land, countryside and wilderness. Even if urban sprawl is a phenomenon as ancient as settled societies (Bruegmann, 2005), it is only as a result of a quasi-globalized industrialism that it has gained truly worrying proportions from the environmental point of view.

Turning to the ecological troubles of mega-cities in the context of a study on vernacular heritage may thus seem less surprising or misplaced (even de-localized). On the contrary, departing from my initial subject matter appears inevitable, since the boundary of urban settlements is vanishing: traditional urban spaces - street, square and lane, cul-de-sac, market place or avenue - have already fallen victim to the urban practices deriving from the Athens Charter. By eliminating spatial boundaries, the Modern-Movement-inspired urban planning has produced an enduring identity crisis in the anthropic milieu ${ }^{13}$. Perhaps more importantly, cultural differences between urban and countryside ways of life (many thousands of years old) have fallen into oblivion. Settlements large and small worldwide are undergoing a process of spatial and cultural uniformization regardless of their geographical setting or particular local specificities.

Such considerations are not meant to offer a platform for complaint. It is necessary instead, from a professional standpoint and without complacency, to begin reconsidering the ongoing transformations of the human habitat in order to assume a clear-headed approach when discussing the conservation of vernacular built heritage. It is also useful to identify what else is at stake beyond the mindful preservation of vernacular buildings, sites, and cultural landscape.

Any project in history was aimed at responding to social commands emanated from smaller or larger groups of humans. We understand the project in the most comprehensive of senses, meaning a territorial arrangement of any size and of any sort planned to accommodate inhabiting. Boundaries were invented to separate settlements, various urban functions, gardens, agricultural fields, tennis courts and so forth. There were boundaries at the edge of landscape gardens, even when they were hidden in order to achieve the aesthetic effect of endlessness. The human project is thus by definition selfreferential.

13 "De toute manière, le tissu urbain devra changer de texture: les agglomérations tendront à devenir des villes vertes. Contrairement à ce qui se passe dans les cités-jardins, les surfaces vertes ne seront pas compartimentées en petits éléments..." Le Corbusier 1971, §35, my underline. First published in 1941 and supposed to be a synthesis of the fourth CIAM (1933) dedicated to the functiona city, this text is in fact a quintessential rendition of Le Corbusier's own conceptions on the matter, and has since 1971 been printed under his name.
If at this stage the idea of a boundary is to be considered at all, it needs to be put in relation with a reference system different from the traditional one, where the function of the boundary can no longer be reduced to exclusion. It seems as if inclusiveness went against the very essence of territorial delimitations. Yet I shall argue for the opposite by citing the example of the failed hydrotechnical project of a large reservoir built in the capital city of Romania, Bucharest ${ }^{14}$.

2.4.2 The inclusive exclusion: Built between 1986 and 1989, what should have been Lake Văcărești was never completed. Instead, its earth and concrete rampart turned into the boundary of an urban enclosure measuring 184 hectares, which today is hosting a rich natural biotope, leading eventually to its legal protection ${ }^{15}$. Once nature took over, taking advantage of the safety provided by the artificial relief, the area was gradually populated by a considerable number of species, thus creating an astonishing anthropic-natural realm. With the emergence of this wilderness in an urban context the overall sense of localness acquired entirely new dimensions.

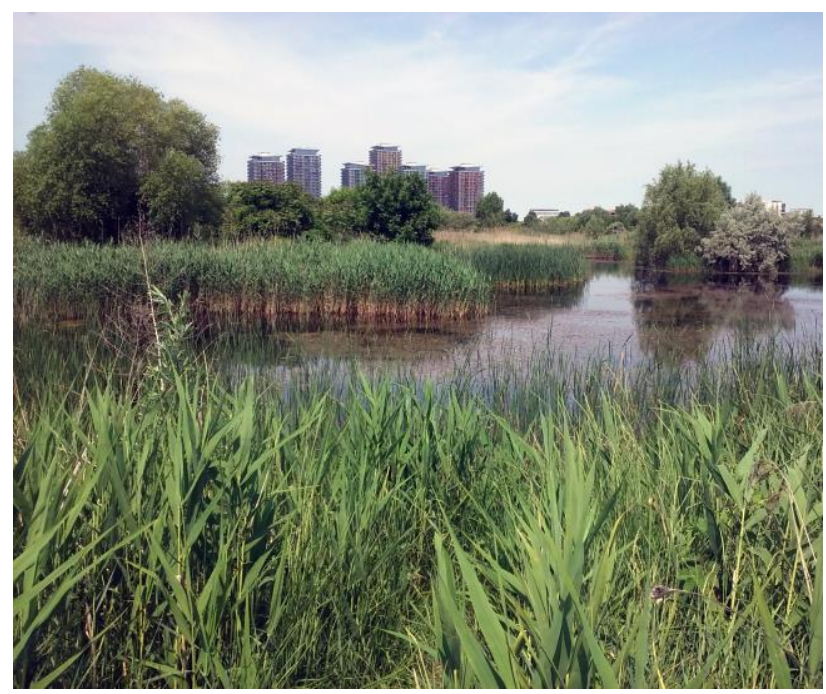

Figure 8. Văcărești nature park,

Bucharest, Romania.

Although the result of a failed project, the exterior part of the Văcărești rampart is somewhat integrated into its urban neighbourhood by means of the habitual urban greenery.

However, its ghastly aspect inside the parc, marked ostentatiously by the slabs of reinforced concrete, is yet to be dealt with (but in this particular case the aesthetic value of the installation is not of utmost importance). Yet this rebarbative rampart inspires solutions for future arrangements. Had the dam been planned to become the urban boundary it is today, its "façade" (and the whole affair) would have looked differently.

\section{CONCLUSION. WHAT LIES BEYOND?}

On the basis of the Văcăreşti experience, we become quite assured that future projects can and must abandon human selfreferentiality in order to incorporate the interests of other species as well. While biodiversity in itself cannot be planned, it can and must be taken into account. If environment is not to be part of a project, it can and must be left to survive alongside our globalised urban realm.

14 https://parcnaturalvacaresti.ro/en

15 The protected status is approved by the Government in 2016 
Multiplying the Văcărești phenomenon, occasionally turning it inside-out, as well as learning from it, could result into planning the new boundaries needed to be drawn between human settlements and natural milieu; this would provide the necessary protection on both sides of the limit, while being also satisfactory aesthetically. Not a wall, not even a rampart, the new species of boundary would work as an intermediate strip ${ }^{16}$, wide enough to create a filter and designed carefully enough to be beautiful.

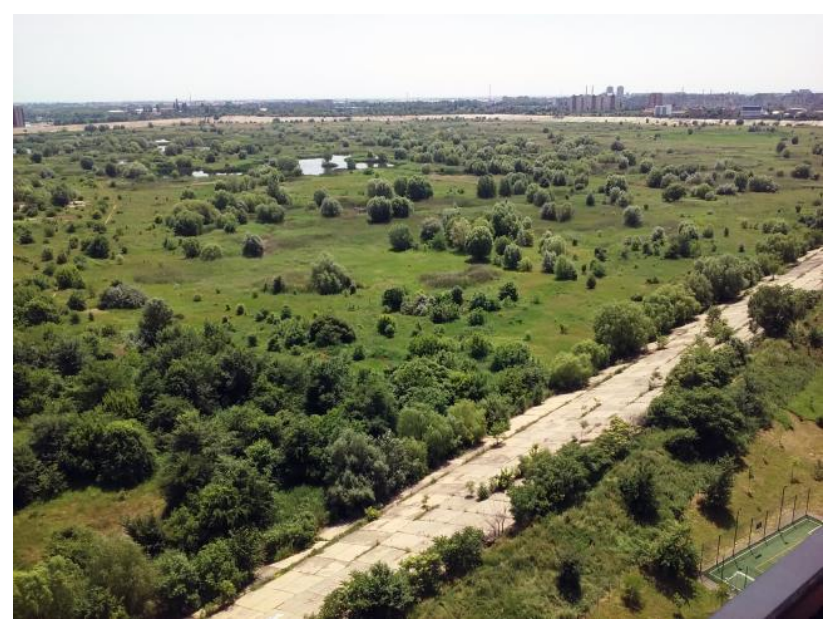

Figure 9. Văcărești nature park, Bucharest, Romania.

What is to be dealt with today and tomorrow, beyond vernacular architecture and the theory and practice of its preservation, is the reinvention of the boundaries for any kind of localness: no longer between town and village, or between different cultures, but between human and natural territories.

The ultimate lesson that built vernacular heritage can teach us is a reasonable integration of human settlements into the environment. Learning it may well be the key to the truer, more sustainable, and comprehensive conservation of vernacular heritage, both material and intangible.

At stake, however, is the thorough reconsideration of what comprehensive architectural necessities will become in the age of the post-vernacular.

\section{REFERENCES}

Berque, A., 2000. Les raisons du paysage, Hazan, Paris

Brandi, C., 1963. Teoria del restauro, Edizioni di Storia e Letteratura, Roma,

Bruegmann, R., 2005. Sprawl, The University of Chicago Press, Chicago

Choay, F., 2006. "Le concept d'authenticité en question", in Pour une anthropologie de l'espace, Seuil, Paris

Jeanneret, C., dit Le Corbusier, 1971. La Charte d'Athènes, Seuil, Paris

16 I owe the idea to Sonja Vangjeli (2017), who proposes separation strips as an arrangement to protect archaeological parcs in Lima. These intermediate urban realms offer functional diversity adapted to both sides of the spatial boundary they put in place.

\section{Kant, I., 1790. Kritik der Urteilskraft}

Kotkin, J., 2006. The City, The Modern Library, New York

Lakoff, G., Johnson, M., 2003. Metaphors We Live By, The University of Chicago Press, Chicago

Magnaghi, A., 2003. Le projet local, Editions Mardaga, Brussels

Mansbach, S. A., 2018. Advancing a Different Modernism, Routledge, New York and London

May, J., Reid, A., 2010. Buildings without Architects, Rizzoli, Milano

Nara Document on Authenticity, 1994

Popescu, C., 2004. Le style national roumain : Construire une Nation à travers l'architecture, 1881-1945, PU Rennes, Rennes

Ruskin, J., The Seven Lamps of Architecture, "The Lamp of Memory", 1889. 6th edition, George Allen, Sunnyside, Orpington,

Ritter, J., 1997. Paysage, Les éditions de l'Imprimeur, Besançon

Rykwert, J., 1981. On Adam's House in Paradise: The Idea of the Primitive Hut in Architectural History, The MIT Press, Cambridge Mass.

The European Landscape Convention, 2000

UNESCO Convention for the Safeguarding of the Intangible Cultural Heritage, 2003

Vangjeli, S., 2017. "Reframing Urban Boundaries: Lima's Urban Black Holes", in studies in History \& Theory of Architecture, vol. 5, Bucharest

Veselý, D., 2004. Architecture in the Age of Divided Representation, The MIT Press, Cambridge Mass.

Webber, M., 1964 (editor). Explorations into the Urban Structure, University of Pennsylvania Press, Philadelphia

\section{CREDITS FOR THE ILLUSTRATIONS}

With two exceptions, the photographs inserted in the text are made by the author who owns their copyright.

Figures 5 and 6 are the work of Szigeti Vajk István who was kind to give them for being published in this form. 